Fecha de recepción: marzo 2020 Fecha de aceptación: abril 2020 Versión final: mayo 2020

\section{Ultrajados, mal pagados y nominados: La violencia simbólica y física sobre los participantes de los reality shows}

Marta Noemí Rosa Casale ${ }^{(1)}$

\begin{abstract}
Resumen: Aparecidos hacia fines del siglo pasado, los reality shows televisivos muy pronto se convirtieron en un boom, debido a que a su comparativamente bajo costo de producción suman el gran interés que despiertan en el público. Bajo el lema "la vida misma" y el atractivo de personas comunes, por primera vez en la pantalla de todos los hogares, programas como Gran hermano o Expedición Robinson llevan la vida íntima de sus concursantes al centro de la escena, mientras los someten a condiciones extremas y numerosos ultrajes en función del show.

Ni simples trabajadores ni estrellas de televisión, los participantes "venden" sus miserias, conservando apenas algunos derechos. Maltratados, aislados y difamados, los elegidos soportan todo con tal de lograr el premio y la fama prometidos. Fama cuyo beneficios han cedido desde el vamos.
\end{abstract}

Palabras clave: Reality shows - violencia física - violencia simbólica - derechos personalísimos - Gran Hermano - panóptico

[Resúmenes en inglés y portugués en la página 100]

(1) Licenciada en Artes Combinadas (UBA). Profesora de Filosofía (UCA). Coautora de Una historia del cine político y social en Argentina, Volúmenes I y II (Nueva Librería, 2009 y 2011) y del Diccionario biográfico estético del actor en Buenos Aires Vol. I (Galerna, 2009). Forma parte del Instituto de Historia del Arte argentino y latinoamericano (Facultad de Filosofía y Letras, Universidad de Buenos Aires) desde 2003 investigando tanto en el área de cine como del teatro.

\title{
Introducción
}

Íntimamente ligada al sistema de estudios que le dio origen, la estrella cinematográfica en sentido estricto desapareció conjuntamente con éstos, aproximadamente a fines de los '50. Sin embargo, con distintas mutaciones, dio lugar a otras construcciones similares en distintos medios, una de las cuales es la estrella televisiva, también ligada a un género 
-fundamentalmente, la telenovela- y a una industria -la de la televisión-. Como la star cinematográfica, la televisiva también tuvo su apogeo y su declinación con la aparición de nuevos géneros y nuevas formas de consumo cultural. A fines del siglo pasado y principios de éste, el surgimiento de los reality shows dio origen a un nuevo tipo de "estrella", con algunas coincidencias en su promoción con la cinematográfica, pero importantes diferencias: la futura "estrella" se convierte en tal durante un proceso al que el espectador puede asistir, en algunos casos, las veinticuatro horas, presenciando aquello que se considera su vida privada (muy especialmente en los shows denominados "de encierro"), mientras no realiza ninguna actividad específica, salvo la de todos los días, con excepción del caso de aquellos realities que suponen el adiestramiento o la competencia en alguna disciplina.

Aunque los participantes firman, al momento de entrar, un contrato acerca de lo que se espera de ellos durante el tiempo que dure su participación en el programa y, se supone, son seleccionados para éste en función de aptitudes especiales que los hacen sobresalir sobre los miles de aspirantes, esta "prestación", descripta con lujo de detalles en dicho documento, pasa desapercibida como "trabajo", ya que se supone que éstos simplemente "viven" en un ámbito convertido en vidriera para el espectador, siempre atento a su "vida privada". Más allá de los dilemas que propone el género mismo -considerado en el límite entre ficción y no ficción-, del hecho de que haya o no guiones, o de que los conflictos surjan espontáneamente o sean favorecidos o provocados, el encuadramiento laboral de los participantes y sus condiciones de vida en ese tipo de shows aparecen como uno de los problemas básicos del formato y la dinámica, notables en los múltiples juicios entablados por los concursantes contra las productoras en diferentes partes del mundo. Por lo demás, e independientemente de la condición (o no) de trabajador de sus participantes, por su misma naturaleza, los shows de encierro parecen poner en cuestión algo más radical que sus derechos laborales, como son sus derechos más íntimos, aquellos que el derecho civil llama "personalísimos" y atañen más directamente a su integridad. Y esto sucede en dos órdenes. En primer lugar, el más obvio, el estrictamente material, que no solo se refiere a la falta de una retribución justa en dinero por un trabajo que la productora se encarga de invisibilizar, sino a posibles daños tanto a la salud física -en riesgo especialmente en los realities que implican condiciones de vida extremas-, como a la psíquica -asediada permanentemente por el confinamiento y la multiplicidad de conflictos creados ad hoc en función del show-. En segundo lugar, pero de igual importancia, en el orden simbólico, en relación principalmente a la imagen, la reputación y la exposición sin límites de la vida privada, particularmente, desde un punto de vista que explota la humillación, afectando el honor del concursante (aquello que más adelante relacionaremos con la violencia simbólica, a partir del concepto acuñado por Pierre Bourdieu).

Maltratados, aislados y difamados, los participantes de los reality shows venden sus miserias sin saber muy bien cuál es el precio que quienes los contratan pagarán por ellas, y, lo que es peor, mucho menos, el precio que ellos mismos pagarán por exhibirlas. 


\section{El reality show: un nuevo género televisivo, un negocio provechoso}

Aparecido entre fines del siglo pasado y principios de éste como un fenómeno global que aconteció más o menos al mismo tiempo en distintos y distantes puntos del planeta ${ }^{1}$, los reality shows se convirtieron en seguida en un boom por su novedad y bajo costo de producción. Esto se debió, en primer lugar, al hecho de traer por primera vez a las pantallas personas "comunes", con vidas similares a las del televidente; vidas que éste está habilitado para "espiar" en cualquier momento, pudiendo, además, emitir juicio sobre sus conductas al votar vía telefónica su futura continuidad en el programa ${ }^{2}$. Este papel sumamente activo del espectador, convertido en juez y co-artífice del show, sumado al carácter supuestamente "espontáneo" y "real" de todo cuanto acontece ${ }^{3}$, constituyen los principales atractivos de la propuesta y uno de los pilares de su éxito. El otro es el importante ahorro en gastos de producción, fundamentalmente, en recursos humanos, ya que -a diferencia de la mayor parte de los programas que los precedieron- este tipo de show no recurre a figuras conocidas, que puedan exigir una más o menos alta retribución por su desempeño, sino a personas anónimas, dispuestas a renunciar a todo con tal de conseguir una fama que, aunque sea transitoriamente, les abra el camino para una promisoria carrera en los medios. Esta considerable rebaja de retribuciones es aplicable, incluso, a los casos en los que los participantes sean celebrities, puesto que éstas, casi siempre, son elegidas entre figuras de segunda línea y, por lo tanto, no perciben un cachet alto; por el contrario, la mayoría de los seleccionados se encuentra en un momento incipiente o de declive en su carrera, por lo que acepta un contrato poco oneroso a cambio de la visibilidad que otorga el formato. Por lo demás, el género no demanda grandes inversiones ni en personal, ni en equipos, ni en decorados, puesto que todo ocurre en un mismo lugar; ni en publicidad, ya que los programas madre replican en múltiples programas satélites que sirven a su difusión (a las emisiones en directo -cuando las hay- se agregan los resúmenes diarios o semanales, las galas, los debates y los programa de chimentos que vuelven sobre lo acontecido, a los que se suman la divulgación en otros medios tales como la prensa gráfica o la web). Además, el show genera sus propios ingresos, dado que la franquicia rápidamente se convierte en una importante usina de merchandising. Por otra parte, la suma dada en concepto de premio, en aquellos programas que prometen una recompensa en dinero, de ninguna manera opaca los importantes beneficios que embolsa la productora. En definitiva, este tipo de shows constituye una manera fácil y barata de completar la grilla y captar audiencia, a la vez que una fábrica de famosos cuya explotación pasará muy pronto a engrosar las arcas de la empresa. No por casualidad los reality shows aparecen en un momento en que se intensifica la competencia y crece el número de canales privados de índole comercial.

Como género el reality show -más difundido como reality game show, show en el que los participantes concursan- es un híbrido que surge en la convergencia de dos vertientes. Por un lado, la llamada Reality TV o Telerrealidad, un macro género que involucra distintos tipos de programas, caracterizados todos ellos por "basar su estrategia enunciativa en el efecto de lo real" (Oliva Rota, 2013, p. 33); es decir, por su capacidad de ser recepcionados como un informe de los hechos tal cual son, independientemente de cualquier manipula- 
ción. Esta vertiente lo emparenta con otras clases de shows basados todos ellos en "hechos reales", tales como el talk show, el court show, los programas de emergencias o rescates, o el docudrama (docusoap) (Longo, 2004).

Por otro lado, el género tiene también sus antecedentes en los clásicos programas de juego y entretenimiento -los game shows- de los cuales puede considerárselo un subgénero. Esta vertiente lo vincula con shows ya fuertemente instalados en la televisión, como los programas de preguntas y respuestas o los concursos, con los que tiene en común la participación de sus protagonistas en una competencia con reglas predeterminadas, un premio en disputa y uno o varios ganadores.

Los reality game shows desde el inicio se presentaron en distintos formatos, que, a su vez, fueron transformándose al agregarse nuevas pautas. La mayoría de ellos siguieron la forma de los pioneros Expedition: Robinson (Expedición: Robinson, Suecia, 1997 en adelante, en EEUU Survivor) y Big Brother (Gran Hermano, Holanda, 1999, en adelante) como "shows de encierro", formato en el que los concursantes tienen que convivir en determinado ámbito, cerrado sobre sí mismo, por una determinada cantidad de tiempo, sin contacto alguno con el exterior ${ }^{5}$, salvo con un presentador, pasando por diferentes pruebas en función de las cuales serán eliminados uno a uno hasta llegar a un ganador. Una variación de este formato son los shows de aprendizaje, como Popstars (Nueva Zelanda, 1999) o The Apprentice (EUA, 2004 en adelante) en los que los participantes adquieren una destreza o la perfeccionan durante la emisión del programa. En el primero, una docena de chicas concursa para formar parte de un grupo vocal femenino, siendo premiadas las finalistas con un contrato discográfico. Mientras dura el concurso van siendo adiestradas en diversas disciplinas relacionadas con la música y el desempeño en shows (ejercitación de la voz, baile, cualidades interpretativas). En el segundo, un grupo de empresarios con experiencia en distintas áreas compite por un premio de un cuarto de millón de dólares y un puesto gerencial en una de las empresas de Donald Trump, quien ofició de magnate/presentador en gran parte de las temporadas y se hizo conocido popularmente a raíz de este programa. A lo largo de las emisiones los participantes deben desarrollar distintos proyectos cuya concreción determinará su permanencia o no en el programa. Tanto uno como otro tipo de show se caracterizan por ser "inmersivos" (Oliva Rota, 2013), es decir, formatos en los que los participantes concursan las 24 horas del día, más allá de que la emisión sea acotada.

Un elemento central que hace a la esencia del género es la autenticidad, característica ésta que se relaciona con su condición de "discurso sobre la realidad" (Amigo, 2004, p.143). Dicha autenticidad es construida en base a la espontaneidad y "veracidad" de todo cuanto sucede frente a cámaras, puesto que, se supone, llega al espectador "libre de toda intervención por parte del director audiovisual, de los camarógrafos, del canal y en general, de los responsables de la imagen y del sonido" (Id.). Este efecto, sin embargo, es el resultado de mecanismos estéticos y narrativos bien determinados, como, por ejemplo, la ocasional baja calidad del sonido y de la imagen, la ausencia de música incidental, la inexistencia de un narrador ya sea intra o extra diegético, y la naturalidad en el accionar de los participantes. Mediante estos recursos, estos shows buscan distanciarse de los programas de ficción, acercándose a la apariencia del documental de observación, según la tipología de Bill Nichols (1997). Un factor importante para el consecución de este resultado es el uso 
de instrumentos de registro automático, fundamentalmente, de cámaras que podrían homologarse a las de vigilancia -comúnmente consideradas las menos intervenidas y prueba en la comisión de delitos- y otras de ese estilo, como las cámaras ocultas o las de visión nocturna.

No obstante, la autenticidad por sí sola no alcanza para atraer a la audiencia; "la vida misma”, en su pormenor, suele carecer de grandes atractivos, de la espectacularidad que demanda el show. Para hacerlo sostenidamente interesante, el género debe recurrir a ciertos procedimientos propios de la ficción, especialmente de la telenovela, construyendo en los resúmenes diarios y semanales historias que puedan ir siguiéndose de manera serial y personajes de distinto tipo, fácilmente reconocibles para el público: el héroe/heroína, el villano/a, la chica sexy. Estos roles se levantan sobre las personalidades reales, previamente seleccionadas en base a sus características individuales, y los conflictos que éstas puedan producir en el enfrentamiento con otras antagónicas.

Es decir, en los reality game shows convergen recursos tanto del documental como de la ficción, ambos opuestos entre sí, pero cuyo conflicto se disimula para transmitir una fuerte sensación de realismo.

Una característica particular de este tipo de espectáculo es el convertir a sus protagonistas, rápida y fugazmente, en "estrellas televisivas", a la vez producto consumible y materia del show; y esto por varias razones. En primer lugar, hay que notar aquí que la star-mediasystem, como denomina Gubern (2006:52) a la "estrella" de televisión, o la "personalidad" (personality), como lo hace Langer, tiene características diferentes y hasta opuestas a la de la star cinematográfica: donde ésta propone distancia, la primera ofrece intimidad; a la excepcionalidad, contrapone familiaridad; la inmediatez de la tv contrasta con la aparición esporádica y remota de la estrella de cine, que protagoniza una película o, a lo sumo, dos al año (Langer, 1981). Estas peculiaridades de la personalidad televisiva -y el cambio de paradigma que comporta- son el correlato de un cambio en el imaginario del espectador, que ya empezó en el cine con producciones más "realistas" y modificaciones en el star system hollywoodense, y se consolidó con la televisión. Debido a que el aparato de tv entra en la propia casa, llevando hasta allí -hasta el centro mismo de la vida doméstica del espectador- todo cuanto ofrece, éste busca en ella figuras más próximas, más cercanas a su propia vida, y, por ese mismo motivo, se interesa cada vez más en los pormenores de la vida privada de aquellos a quienes frecuenta por ese medio. Una creciente industria editorial, que se basa precisamente en la divulgación de la intimidad de estas figuras, ayuda a consolidar su fama.

Esta capacidad de la televisión para crear fama se vuelve más notoria a medida que el medio se torna más y más autorreferencial, es decir, se vuelca más sobre sí mismo y menos sobre la realidad extra-televisiva; crea su propia realidad y a sus protagonistas, como sucede con los participantes de los realities. Así el medio engendra y alimenta estrellas fugaces, que descarta cuando se agota su rentabilidad; solo sobreviven, no sin dificultad, aquéllas que saben integrarse con éxito en el negocio televisivo. 


\section{¿"Vender" la propia vida? De la sesión de derechos a la pérdida del honor. La violencia simbólica}

Los participantes de los reality shows pasan mucho tiempo frente a las cámaras, para ser exactos, 24 horas al día, mientras dura su participación ${ }^{6}$. Por contrato, en ese período no pueden abstraerse de ellas (por otra parte, sería imposible, salvo que se las dañara adrede) o dejar de utilizar el micrófono que portan y registra todo cuanto dicen. Las cámaras los graban cuando duermen o se duchan, cuando comen o discuten. Por lo demás, depende del programa, su rutina puede no involucrar ninguna tarea en especial, salvo el mantenimiento del lugar en el que viven y las pruebas semanales que deben cumplir. Este es el caso de Gran Hermano, por ejemplo, el más paradigmático de todos; en otros, como en Expedición Robinson, se añaden a estas labores las relacionadas con el abastecimiento de comida. Otros formatos suman a las actividades básicas (que no son específicamente "artísticas") las vinculadas con el perfeccionamiento de sus habilidades en el ámbito al que apunta el show - por ejemplo, en canto, baile, desempeño escénico y expresión corporal, en Operación Triunfo (España, 2001, en adelante), el reality que busca y produce talentos musicales- o una labor específica, como sucede con El bar (Suecia, 2000, en adelante), el show en el que los participantes deben regentear un establecimiento de ese tipo y producir ganancias.

Por su participación, los concursantes en estos shows reciben, depende de en qué formato se desempeñen, además del premio para el ganador, un pago en dinero cuya suma es muy variable. En Gran Hermano "los hermanitos" perciben una suma mínima por cada semana de encierro que pasan en la casa, suma que no se les entrega directamente, sino que se les deposita en el banco para que puedan disponer de ella cuando salgan -curiosamente, tal como sucede con los presos-. Por otro lado, en Operación Triunfo los participantes-artistas solo reciben retribución por los conciertos que den o las publicidades que hagan en las redes, no teniendo remuneración alguna por el tiempo que pasan en la Academia en la que transcurre el programa.

Esta ausencia o escasez de retribuciones para los protagonistas puede, a primera vista, parecer normal. Es muy difícil ver a estos "competidores" como trabajadores, ya que, en muchos casos, parecen "no hacer nada" en especial, salvo participar en la competencia, con el beneficio, además, de la fama que ello comporta, una fama que deviene un capital simbólico que el participante, supone, podrá conservar más allá de los límites de ese contrato puntual, cuyos mayores réditos usufructuará la productora por dos o tres años. Sin embargo, ni la vida en el encierro ni las retribuciones logradas por ello, finalmente, resultan tan idílicas como los protagonistas podrían presuponer. Al respecto dice la abogada Ana Rosenfeld, letrada de un grupo de ex participantes de Gran Hermano 1 y 2 Argentina, que litigan con la productora Endemol y el canal de aire TELEFÉ (Televisión Federal S.A.) en varios frentes: "Sus contratos eran lesivos al honor y las buenas costumbres, porque por un pago irrisorio ( $\$ 500$ semanales) se apropiaban eternamente de la persona. Al firmarlos, los participantes no tuvieron ningún asesoramiento letrado, y por la ambición de entrar firmaban cualquier papel" (PrimiciasYa, 7/5/11). En estas breves declaraciones aparecen ya los dos conflictos fundamentales que los reality game shows conllevan desde su misma esencia: uno de orden simbólico, relacionado con la imagen, la reputación y la exposición ilimitada de la vida privada desde un punto de vista basado en la humillación; 
otros de orden estrictamente material, que no solo se refieren a la falta de una retribución justa en dinero por un trabajo invisibilizado por la productora, sino a posibles daños tanto a la salud física (especialmente en los realities que implican condiciones de vida extremas), como a la psíquica.

En cuanto al primer punto, es claro que al acceder a ser filmado y grabado veinticuatro horas al día el participante cede en primer lugar el derecho a su imagen y su intimidad, derechos que, por otra parte, parecen básicos e inalienables ya que están garantizados por la Constitución Nacional, pero a los que una persona puede renunciar voluntariamente, puesto que se hallan bajo la potestad de cada individuo (Mattera, 2016; Martrat Martí, 2016). Muchos autores, al encuadrar laboralmente a los participantes de estos game shows, hacen hincapié en esta llana cesión de derechos como la base de la relación que los "concursantes" establecen con la productora; visto así, éstos parecerían limitarse a "vender" su vida privada al comprometerse a llevarla adelante frente a las cámaras, no ofreciendo ninguna otra "contraprestación" a cambio de los beneficios a obtener. A pesar de ser consensuada y en apariencia inocua, esta renuncia comporta innumerables consecuencias, algunas sumamente riesgosas para los participantes, en especial en cuanto a daño moral se refiere.

Aunque la ley argentina las trata separadamente, imagen e identidad están intrínsecamente ligadas a la dignidad, el honor o la estima social, según consta en la misma legislación (Mattera, 2016); por lo tanto, no es extraño que el daño a la reputación sea uno de los principales perjuicios que registran los participantes. Iguales reclamos se suceden en los programas de distinto formato y diferentes países. Así, en Argentina, "Walter Mouso, concursante del reality Confianza ciega ${ }^{7}$ se queja por haber sido presentado por Juan Castro, animador del ciclo, como bisexual y haber perdido a su novia por eso", además de "haber sido rotulado por los editores como 'el puto"', y Alejandro Restuccia reclama por su fama de "fiestero" y "tener sexo con animales" (fuente webconferencia.net/gran-hermano-5-foro-central). Algo similar sucede con los participantes de los realities españoles, quienes se lamentan de no conseguir trabajo tras haber pasado por el show debido a las "etiquetas" que les han puesto. El militar zaragozano Jorge Berrocal sintetiza la situación con palabras parecidas a las de otros participantes: "Cuando la telerrealidad explota, salpica a todos, genera etiquetas y te condiciona para el resto de tu vida" (Moreno, 2019). Estos efectos -no previstos por los concursantes al momento de firmar el contrato- se dan porque, tal como puntualizan Terribas y Puig (citados por Oliva Rota, 2013: 40), éstos "no gozan de los mecanismos necesarios de protección ante el programa". La experiencia termina por convertirse para ellos en "el caso extremo de la pérdida de control sobre la propia vida", debido a que su estadía se desarrolla en un espacio construido y dominado por quienes manejan arbitrariamente el juego y detentan todo el poder.

En su análisis de los mecanismos puestos en juego en estos shows, Jelle Mast (2016) destaca cuatro formas fundamentales de maltrato a los participantes que terminan en la producción de daño moral: la intrusión, la humillación, la tergiversación en la representación y la apropiación sin límites de la imagen. En cuanto a la intrusión, Mast señala principalmente el uso subrepticio de cámaras en miniatura o no visibles por los participantes, dispositivos que vulneran las zonas de la mayor intimidad, transgrediendo los códigos de lo que sería el espacio más privado. Con relación a la humillación, el investigador puntualiza la preferencia por el registro de momentos de debilidad de los concursantes; es decir, las ocasiones en las 
que éstos se hallan afectivamente quebrados o avergonzados, en situaciones ridículas o reñidas con el decoro, situaciones que, por otra parte, propicia la Producción. La tergiversación se refiere más precisamente a la construcción de la imagen de cada participante mediante un recorte tendencioso de la información (las "etiquetas" a las que aluden los concursantes), pero también a la falta o distorsión de la data proporcionada a los ingresantes en el momento de firmar el contrato, tal como manifiesta Rosenfeld. Por último, la apropiación sin límites de la imagen involucra las cláusulas más leoninas del contrato, que hacen al uso irrestricto "del nombre, la (auto) biografía, historias o imágenes de los concursantes [...] en todo el mundo y sin limitación temporal alguna" (el "eternamente" al que se refiere la abogada, lo que Mast denomina sencillamente "explotación") $(2016,2186)^{8}$. Mientras que la última forma de maltrato se relaciona sobre todo con una pérdida del orden económico, las otras tres se refieren más específicamente a la violencia simbólica.

Para Pierre Bourdieu (2001), el primero que analizó este tipo de violencia, la violencia simbólica es aquella que impone significaciones, disimulando las relaciones de fuerza (esto es, de poder) que lo permiten. Dichas significaciones construyen un imaginario que tiene tendencia a plasmarse en un orden gnoseológico, o sea, a constituirse como una "verdad" aceptada dentro de determinado grupo social. Esta selección de significados no surge naturalmente, sino que es arbitraria y se basa en necesidades de la clase dominante (en el caso de los realities que analizamos, concretamente, de la Producción), que los impone en función de sus intereses, terminando por naturalizarse por el concurso de todo el grupo, es decir, tanto de quienes dominan como de quienes son dominados.

Uno de los modos de manifestarse esta violencia simbólica es la construcción de los estereotipos que circulan en determinada sociedad o grupo social. Estos se fundan, precisamente, en la capacidad de aquellos que detentan el poder de establecer modos de ver y de relacionarse que tienen por efecto determinar la forma en que un grupo de personas debe ser representado. En el caso de los realities, la construcción de un determinado participante dentro de un marcado estereotipo - por lo general, desvalorizante- es resultado de procesos ficcionales que buscan hacer de la narración de base, que instituye el programa, un producto televisivo más simple y atractivo para el público. Una prueba del rol fundamental de los estereotipos dentro del show es el papel preponderante que tiene la descripción de éstos en el know-how que se vende conjuntamente con el formato del programa. Bourdieu mismo pone de manifiesto esta capacidad de la televisión para manipular los contenidos cuando puntualiza su poder para mostrar "algo distinto de lo que tendría que mostrar si hiciera lo que se supone que se ha de hacer, es decir, informar", o para "elaborarlo de tal modo que tome un sentido que no corresponde en absoluto con la realidad" $(1997,24)$. Y esto es así porque es en la comunicación, según el sociólogo francés, donde se tejen las redes de poder y donde lo simbólico "puede producir su efecto propio, o sea, propiamente pedagógico", puesto que solo allí "se dan las condiciones sociales de la imposición y de la inculcación” (2001, p.47). Por tal motivo, los mass media constituyen un lugar de privilegio para el accionar del poder simbólico (aunque no el único), pues ellos son, quizás más que cualquier institución, quienes pueden "hacer ver y creer a la audiencia que [estos significados] están de acuerdo con la visión, el actuar y con la totalidad del mundo, representado en las creencias que se depositan en la legitimidad de lo que se expresa" (Gallegos, Gómez, Imaz, y Paredes, citado por Hincapié Adarme, 2015, p. 9). 
En este sentido, y en relación con el show, las lesiones a la reputación constituyen uno de los efectos más notables de la violencia simbólica ejercida sobre los participantes y uno de los que más rápidamente influyen en su capital simbólico, trayendo consigo los subsiguientes perjuicios económicos, ya que es la cuantía de este lo que determina el puesto de cada individuo en la sociedad y, con éste, también sus posibilidades laborales, de promoción social, etc. (Hincapié Adarme, 2015).

\section{Cuerpos y mentes violentados: los daños físicos y psicológicos}

Aunque los shows "extremos"-es decir, aquellos que someten a los participantes a condiciones de vida sumamente duras- son el ejemplo más paradigmático de la agresión a la salud física que propician estos realities, éstos no son los únicos en los que la salud de los participantes sufre riesgos; en todos los formatos, en cual más, en cual menos, el bienestar y la integridad de los competidores están puestos en juego. Y no solo de los competidores, la violencia sobre cuerpos y mentes llega a cada uno de los involucrados en el programa. En 2013, por ejemplo, se suicidó el médico del reality francés Koh-Lanta -un programa de supervivencia al estilo Survivor que se rodaba en Camboya- debido a la presión de los medios, quienes lo responsabilizaban por la muerte de uno de los participantes debido a un paro cardíaco. El joven, de veinticinco años, se había descompensado durante una prueba de natación el primer día y, según su familia, no habría recibido la atención necesaria. Una suerte semejante sufrió en 2019 el actor y modelo taiwanés-canadiense Godfrey Gao, quien colapsó y luego murió en circunstancias parecidas mientras filmaba el noveno episodio de Chase me, el reality show chino en el que los competidores juegan carreras durante la noche. No es necesario recalcar aquí que en los realities en los que el aislamiento se realiza en condiciones vitales absolutamente desfavorables o de competencia de gran exigencia física, el daño de los participantes es mayor, y así lo revela su cuerpo, adelgazado por la falta de alimento; dañado por el sol; llevado al máximo de su rendimiento, hasta el límite mismo de lo compatible con la vida.

Otro tanto acontece con la salud mental de los participantes. Baste señalar en este punto la cantidad de problemas de orden psicológico o psiquiátrico que surgieron durante el transcurso mismo de este tipo de shows. Quizás uno de los ejemplos más sobresalientes sea el del concursante de Gran Hermano Polonia Ireneusz Grzegorczyk quien enloqueció durante el certamen y debió ser sacado de la Casa con una camisa de fuerza; algo similar a lo ocurrido en Argentina con Pablo Heredia de Gran Hermano 2, quien pidió salir del encierro pero fue retenido contra su voluntad durante tres días, tras lo cual tuvo un brote psicótico. No obstante, puede considerarse el caso de Sinisa Savija, de 34 años, de la primera edición de Expedition Robinson uno de los más extremos, ya que el joven se lanzó a las vías del tren cuatro semanas después de regresar del rodaje del reality en Malasia, tras haber sido eliminado en la primera ronda. Puesto que el programa no se transmite en directo, sino solo después de haber sido completado el ciclo, y el episodio sucedió antes de su lanzamiento, la participación de Savija pudo ser borrada casi completamente en la edición de la competencia, minimizando el impacto (negativo) en la audiencia. Igual procedimiento se siguió en la TV británica cuando se quitó del aire el reality The Jeremy 
Kyle Show, un programa que también recurre a la humillación de sus participantes, una vez que uno de éstos se suicidó en su casa tras ser sometido a una prueba con un detector de mentiras. El formato es, como queda claro, por su misma esencia, una máquina de usar y desechar material humano.

Por supuesto, no todas las formas de violencia a las que son sometidos los concursantes tienen consecuencias tan radicales. Entre las más sutiles se halla aquella que convierte los cuerpos en "espectáculo" (aquello que Horacio Pérez-Henao llama "cuerpo espectáculo"), $\mathrm{y}$ tiene que ver con la forma en la que son mostrados los cuerpos de los participantes, convertidos en el centro de la escena, principalmente (pero no solo) en los shows que lo tienen como protagonista, como, por ejemplo, en Extreme Makeover (EEUU, 2002-2007; con diferentes nombres en distintos países) o El cisne (2004, EEUU)-, es decir, aquellos que giran alrededor de intervenciones quirúrgicas para cambiar su apariencia. En estos programas, al igual que en aquellos que buscan su mayor rendimiento, el cuerpo de los participantes no solo es "forzado" a encajar en un modelo ideal, sino que, previamente, es mostrado en planos que lindan con la degradación, desnudos, destacando sus más mínimos defectos o imperfecciones, para luego dar cuenta del proceso de transformación, haciendo hincapié en todos los padecimientos físicos que permiten que el participante considerado "patito feo" se convierta en el espléndido "cisne" del final, según la misma terminología del programa. En todos los casos, está de más decir, nunca violencia es solo física, sino que conlleva otros modos tanto psicológicos como simbólicos ${ }^{10}$.

\section{Conclusiones. El sufrimiento como espectáculo}

Todas estas formas de violencia no son un efecto colateral de las pruebas o instancias a las que son sometidos los participantes, sino el foco mismo de interés del programa. La mostración de su dolor tanto físico como emocional, su humillación constante, constituyen la materia principal para atraer a un público siempre en busca de emociones fuertes, deseoso de "deleitarse" con "los infortunios y sufrimientos de los demás", como bien observaba Edmund Burke en 1757, bastante antes del auge de los mass media (citado por Sontag, 2005, p. 111). Si bien es cierto que, cuando firman el contrato, los participantes se avienen a ser expuestos de la forma que determine la Producción, y a pasar por las situaciones y desafíos que ésta proponga, es igualmente cierto que en ese momento los concursantes no son informados de todas las consecuencias que su aparición en la pantalla puede traer, ni las pueden prever en su totalidad. El contrato al que deben atenerse es, quizás, el primer acto de violencia al que son sometidos, por más consentimiento que haya. Por supuesto, después de las primeras ediciones de estos shows, los participantes se han vuelto más conscientes de los riesgos y lo perjudicial de ciertas pautas, y determinadas reglas tuvieron que modificarse, aunque en esencia los distintos formatos siguieron funcionando en base a lo mismo: el dolor y el escarnio de los competidores, como queda demostrado en los ejemplos que remiten a casos muy recientes, citados más arriba.

Entre todas las formas de violencia, la violencia simbólica es la que, probablemente, ocasione los daños más masivos y perdurables, aunque el sometimiento a pruebas de exigencia física superlativa haya llevado a más de un participante a perecer durante el certamen y 
el encierro provocara en varios de ellos brotes psicóticos que inevitablemente dejan secuelas. Y esto es así porque las lesiones al honor -en definitiva, la pérdida de una buena reputación- son un efecto muy generalizado y difícil de superar, ya que implican una mengua importante del capital simbólico del participante y es este capital el que, como sostuvimos antes, determina su posición social y consiguientes posibilidades de progreso. Por lo demás, esta pérdida es algo que acontece a todos los concursantes, porque la reputación es, más que nada, aquello que éstos ponen en juego cuando se comprometen a ser filmados veinticuatro horas y encerrados sin contacto con el exterior durante varios meses.

Por último, otra cuestión igualmente relevante tiene que ver con la condición de trabajador de los participantes y, por lo tanto, con su derecho a una retribución justa no solo en dinero. Este ha sido el principal reclamo que muchos de ellos han llevado ante la Justicia, tanto en la Argentina como en otros países. La suerte de éstos en sus demandas ha sido diversa, no solo por la falta de reconocimiento de su labor específica como "artista en espectáculos públicos", para usar la categorización utilizada para la actividad en España, sino por no reconocérsele la relación de dependencia con la empresa, aunque ésta sea fácil de probar. En este hecho tiene un peso negativo el haber firmado un contrato leonino en el que renuncia de antemano a casi todo, tanto como la posible ambigüedad de su tarea. La relación de dependencia es un punto importante en las disputas legales porque comporta beneficios distintos a los de otras categorizaciones, como son las vacaciones pagas, la jornada laboral de determinadas horas, el descanso semanal, etc.

Evidentemente, con el correr de los años -casi 20- estos shows han ido evolucionando y, con ellos, también los participantes. Los concursantes de las nuevas ediciones son mucho más conscientes de qué pueden perder o ganar con su paso por el programa; están más al tanto de sus derechos y, además, en muchos países ya hay jurisprudencia al respecto. A pesar de todos los reclamos ante la Justicia y las lastimosas declaraciones de muchos ex-participantes, el atractivo sigue siendo grande, puesto que estos realities -sobre todo los que "cazan" talentosson una gran oportunidad ( $\mathrm{y}$, la mayoría de las veces, la única) de acceder a un medio que promete buenas remuneraciones y los réditos de la fama. A juzgar por el éxito que todavía tienen, son muchos están dispuestos a correr el riesgo que implican.

\section{Notas:}

1. Un poco más tarde en Asia y África.

2. No en todos los formatos el público vota quién será expulsado, ni en todos está habilitado para ver lo que sucede en directo las veinticuatro horas.

3. "El secreto del programa es algo que ya hemos dicho en varias ocasiones: es una telenovela de la vida real" Roberto Ontiveros, director de las seis primeras temporadas españolas de Gran Hermano (citado por Oliva Rota, 2013, 35).

4. Otra variante en la que los participantes no concursan es la llamada contrieved reality $t v$, especie de docudrama que sigue la vida de una o varias personas que se mueven libremente, evolucionando en distintos ambientes (reales), en los que son sometidas, adrede, a algún elemento externo que modifica sus vidas. Es el caso de The real world (EUA, 1992 en adelante), considerado un precedente de Big Brother, o Wife Swap (UK, 2003 en adelante). 
5. No en todos. En El bar, por ejemplo, los doce participantes conviven y son filmados las 24 horas, pero se desenvuelven en "el mundo real", ya que deben regentear un bar al que acuden clientes reales. Depende los países, los participantes pueden ver televisión o realizar una visita grupal a algún lugar en especial.

6. Algunos formatos son más benignos y limitan la cantidad de horas de exposición a las cámaras.

7. Reality basado en La isla de la tentación, programa que pone a prueba la fidelidad de un grupo de parejas al someterlas a distinto tipo de tentaciones.

8. La traducción del inglés es mía.

9. Según Fernández Poncela los estereotipos son "preconcepciones generalizadas, parte del proceso mental que organiza la información recibida, simplifica el entendimiento para aprehender el ambiente social, predecir acontecimientos, formar categorías sociales y económicas, hacer más sencilla la percepción de la realidad"; "son ideas, imágenes mentales simplificadas, conjuntos de creencias aceptadas y compartidas culturalmente en la historia, que evalúan y justifican el actuar" (2011, p. 318). Bourdieu pone de manifiesto los poderes de orden simbólico que contribuyen a instalarlos y consolidarlos.

10. La relación entre fuerza física y violencia simbólica se encuentra en forma explícita en Bourdieu (2001, p.50).

\section{Bibliografía}

Amigo, Bernardo (2004). "Para comprender el Reality Show" en Revista Praxis $N^{\circ}$ 6, Santiago de Chile: Facultad de Ciencias Humanas y Educación de la Universidad Diego Portales 139-151.

Bourdieu, Pierre y Passeron, Jean-Claude (2001). "Fundamentos de una teoría de la violencia simbólica" en La Reproducción. Elementos para una teoría del sistema de enseñanza. Libro1. España: Editorial Popular 15-85.

Bourdieu, Pierre (1997). Sobre la televisión. Barcelona: Anagrama

Busquet Duran, Jordi (2012) "El fenómeno de los fans e ídolos mediáticos: evolución conceptual y génesis histórica” en Muela Molina, Clara y Baladrón Pazos, Antonio J. (coord.) Dossier Jóvenes: Ídolos mediáticos y nuevos valores, Revista de Estudios de Juventud $N^{\circ} 12$, marzo 2012.

Escudero Manchado, Lara y Gabelas Barroso, José Antonio (2016) "La realidad de la telerrealidad: escáner de una sociedad (híper) televisiva” en Revista Mediterránea de Comunicación, 7(1), 91-117. Disponible en http://mediterraneacomunicacion.org/. DOI: http://dx.doi.org/10.14198/MEDCOM2016.7.1. Consultado 18/2/2020

Fernández Poncela, Anna María. (2011). "Prejuicios y estereotipos" en Revista de antropología experimental $N^{\circ} 11$ texto 22, 317-328. Recuperado de: https://revistaselectronicas. ujaen.es/index.php/rae/article/view/1932/1682. Consultado 29/2/2020

Gubern, Román (2006). El eros electrónico. México: Taurus.

Hill, Annette (2015). Reality shows. London and New York: Routledge. 
Hincapié Adarme, Luisa María y ot. (2015). "La representación de la violencia simbólica ejercida sobre el hombre y la mujer en las páginas de someecards en español y tarjetas sarcásticas de Facebook durante mayo y junio 2014" en Revista Hojalata N 7 - Noviembre-Diciembre 2015, Colombia: Universidad de Manizales.

Langer, John (1981). “Television's 'personality' system” en Media, Culture and Sociality. New York: Sage, 351-365.

Longo, Fernanda (2004). "Gran Hermano: el juego de "sé tú mismo" en Mimeo. Disponible en http://www.juliangallo.com.ar/wp-content/uploads/2007/01/gh-2007.pdf Consultado $17 / 2 / 2020$

Maldonado Montoya, Juan Pablo (2009). "El trabajador del reality show” en Revista del Ministerio de Trabajo e Inmigración, $n^{\circ}$ 83, 355-372.

Martrat Martí, Joaquim (2016). Concursantes de Televisión y Productora. ¿Trabajo por cuenta ajena o por cuenta propia? El caso del Reality Show. Trabajo de Grado. España: Universidad de Tarragona.

Mattera, Marta del Rosario (2016). “Derechos personalísimos: afectación simultánea de imagen e identidad (Precedentes jurisprudenciales y doctrinarios y el nuevo ordenamiento)" en Wüst, Graciela C. (directora) Estudios de Derecho Privado: comentarios al nuevo Código Civil y Comercial de la Nación. Ciudad Autónoma de Buenos Aires: Asociación de Docentes de la Facultad de Derecho y Ciencias Sociales de la Universidad de Buenos Aires, 215-238.

Mast, Jelle (2010). “The Dark Side of Reality TV: Professional Ethics and the Treatment of Reality Show Participants” en International Journal of Communication $N^{\circ} 10$, EEUU: USC Annenberg Press, 2179-2200.

Moreno, M (2019) "La ruina económica de ser concursante de 'Gran Hermano”" en ABC Edición digital 16/3/19. Disponible en https://www.abc.es/play/television/noticias/abci-ruina-economica-concursante-gran-hermano-201903160102_noticia. html?ref=https\%3A\%2F\%2Fwww.google.com\%2F Consultado 15/08/19.

Nichols, Bill (1997). La representación de la realidad. Cuestiones y conceptos sobre el documental, Buenos Aires: Paidós.

Oliva Rota, Mercè (2013). Telerrealidad disciplina e identidad: Los makeover shows en España. Barcelona: Editorial UOC.

Pérez-Henao, Horacio (2001). El cuerpo narrado en el reality show. Un estudio sobre Cambio extremo. Colombia: Universidad de Medellín/Sello Editorial.

Sontag, Susan (2005). Ante el dolor de los demás. Madrid: Punto de Lectura.

Walzer, Alejandra (2009). “Pedagogías del cuerpo. La construcción espec(tac)ular del cuerpo femenino en el reality show español" en Revista Latina de Comunicación Social, 64, 203 -209. La Laguna (Tenerife): Universidad de La Laguna, recuperado el 27/5/19. Disponible en: http://www.revistalatinacs.org/09/art/18_817_24_U3CM/Alejandra_Walzer.html

DOI: 10.4185/RLCS-64-2009-817-203-209 Consultado 17/2/2020 


\begin{abstract}
Appeared towards the end of the last century, reality shows soon became a success, since they combine in themselves a low cost of production with the great interest they arouse in the public.

Under the slogan "life itself" and the appeal of ordinary people, for the first time on home screens, programs such as Big Brother or Robinson Expedition put the private life of their contestants in the spotlights, while subjecting them to extreme conditions and numerous outrages to gain audience.

Neither workers nor TV stars, participants "sell" their miseries, retaining just a few rights. Battered, isolated and defamed, the selected endure everything in order to achieve the promised prize and fame. Fame whose benefits have given way since the beginning.
\end{abstract}

Keywords: Reality shows - physical violence - symbolic violence - personal rights - Big Brother - panoptic

Resumo: Aparecidos no final do século passado, os reality shows logo se tornaram um sucesso, pois combinam em si um baixo custo de produção com o grande interesse que despertam no público.

Sob o lema "vida em si" e o apelo das pessoas comuns, pela primeira vez nas telas domésticas, programas como Big Brother ou Robinson Expedition colocam a vida privada de seus concorrentes em foco, enquanto os sujeitam a condições extremas e inúmeros ultrajes para ganhar audiência.

Nem trabalhadores nem estrelas da TV, os participantes "vendem" suas misérias, mantendo apenas alguns direitos. Maltratados, isolados e difamados, os selecionados suportam tudo para alcançar o prêmio e a fama prometidos. Fama cujos benefícios cederam desde o início.

Palavras chave: Reality shows - violência física - violência simbólica - direitos pessoais Big Brother - panóptico.

[Las traducciones de los abstracts fueron supervisadas por el autor de cada artículo] 